\title{
Simvastatin ameliorates glomerulosclerosis in Adriamycin-induced-nephropathy rats
}

\author{
Wei Zhang • Qiu Li $\cdot$ Lijia Wang $\cdot$ Xiqiang Yang
}

Received: 3 December 2007 /Revised: 1 June 2008 / Accepted: 3 June 2008 / Published online: 13 September 2008

(C) The Author(s) 2008. This article is published with open access at Springerlink.com

\begin{abstract}
The aim of this study was to investigate the effects of simvastatin, a competitive inhibitor of 3-hydroxy-3methylglutaryl-coenzyme A (HMG-CoA) reductase, on inflammation and glomerulosclerosis in Adriamycin (ADR)-induced nephropathy. Male Sprague-Dawley rats were randomly divided into control, ADR nephrosis, and simvastatin-treated ADR nephrosis groups. ADR nephropathy was induced by a single-tail intravenous injection of ADR $(6.5 \mathrm{mg} / \mathrm{kg})$. Anti-inflammatory effects of simvastatin were studied by evaluating the expression of the inflammatory mediators interleukin-1 beta (IL-1 $\beta$ ), transforming growth factor- $\beta 1$ (TGF- $\beta 1$ ), and transcription factor nuclear factor kappa $\mathrm{B}(\mathrm{NF}-\mathrm{kB})$. In addition, renal function, serum lipid levels, and histopathology were compared between groups. Simvastatin significantly decreases IL-1 $\beta$ and TGF$\beta 1$ expression and NF- $\mathrm{KB}$ activation, accompanied by significant attenuation of glomerulosclerosis and renal function at 12 weeks after ADR injection, and these changes occurred in the absence of lowering of serum lipids. These results suggest that overexpression of inflammation in the renal region may contribute to development of glomerulosclerosis in ADR-induced-nephropathy rats, and simvastatin treatment prevented glomerulosclerosis independent of the lipid-lowering effects. The beneficial effect of simvastatin might be mediated by the effect of anti-inflammatory action through a reduction of NF- $\mathrm{KB}$ activation, and IL- $1 \beta$ and TGF- $\beta$ expression.
\end{abstract}

\footnotetext{
W. Zhang $\cdot$ Q. Li $(\bowtie) \cdot$ L. Wang $\cdot$ X. Yang

Department of Nephroimmunology,

Children's Hospital of Chongqing Medical University,

Chongqing, People's Republic of China

e-mail: liqiu809@hotmail.com

Q. Li

Centre for Lipid Research, Chongqing Medical University,

Chongqing, People's Republic of China
}

Keywords Adriamycin - Nephrosis rats .

Glomerulosclerosis · Interleukin-1 beta $\cdot$ Nuclear factor kappa B - 3-hydroxy-3-methylglutaryl-coenzyme A reductase inhibitor

$\begin{array}{ll}\text { Abbreviations } & \\ \text { IL-1 } \beta & \text { interleukin-1 beta } \\ \text { ADR } & \text { Adriamycin } \\ \text { MCNS } & \text { minimal-change nephrotic syndrome } \\ \text { HMG-CoA } & \text { 3-hydroxy-3-methylglutaryl-coenzyme A } \\ \text { PBS } & \text { phosphate-buffered saline } \\ \text { ALB } & \text { albumin } \\ \text { TC } & \text { total cholesterol } \\ \text { TG } & \text { triglyceride } \\ \text { LDL } & \text { low-density lipoprotein } \\ \text { Cr } & \text { creatinine } \\ \text { ELISA } & \text { enzyme linked immunosorbent assay } \\ \text { H\&E } & \text { hematoxylin and eosin } \\ \text { PAS } & \text { periodic acid-Schiff } \\ \text { GSI } & \text { glomerulosclerosis index } \\ \text { RT-PCR } & \text { reverse transcription polymerase chain } \\ & \text { reaction } \\ \text { GN } & \text { glomerulonephritis } \\ \text { GBM } & \text { glomerular basement membrane } \\ \text { TGF- } \beta 1 & \text { transforming growth factor beta 1 } \\ \text { NF- } \text { B } & \text { nuclear factor kappa B } \\ & \end{array}$

\section{Introduction}

Massive proteinuria and hyperlipidemia are important manifestations of minimal-change nephrotic syndrome (MCNS). Protein and lipids escaping through damaged glomeruli could "stress" intrinsic renal cells [1]. It has been 
reported that interleukin-1 beta (IL-1 $\beta$ ) can only be released by cells under stress conditions [2]. IL-1 $\beta$ is a primary proinflammatory cytokine, which is proposed as a major mediator in both the initiation and progression of glomerulosclerosis [3]. Glomerulosclerosis is the end stage of MCNS; however, few studies have been performed to elucidate the role of IL-1 $\beta$ on the development of glomerulosclerosis in MCNS.

Statins are competitive inhibitors of 3-hydroxy-3-methylglutaryl-coenzyme A (HMG-CoA) reductase, the key enzyme that regulates synthesis of cholesterol from mevalonic acid by suppressing the conversion of HMG-CoA [4]. Because of this activity, the clinical use of statins has produced a significant reduction in cardiovascular-related morbidity and mortality in patients with established cardiovascular disease and hypercholesterolemia $[5,6]$. In addition, several beneficial effects of statins have been described in experimental models of renal disease, including streptozotocin-induced diabetic nephropathy [7], puromycin-induced nephrosis [8], and chronic cyclosporin A (CsA)-induced nephropathy [9]. Nevertheless, the effect of statins in a rat model of Adriamycin (ADR) induced nephropathy has not been reported, which characterized experimental analogue of human MCNS.

Although it is widely accepted that the clinical benefit obtained with statins is a direct result of their lipid-lowering properties, there is still debate as to whether the additional so-called pleiotropic effects of statins contribute to the clinical outcome in renal disease or whether all beneficial effects of statins are due to lowering plasma lipids. Recently, accumulating evidence has suggested that statins have pleiotropic effects independent of plasma lipid lowering [10].

Hence, this study was performed to investigate the role of renal-region inflammation on the development of glomerulosclerosis in ADR-induced-nephropathy rats and whether simvastatin had an anti-inflammatory effect independent of plasma lipid lowering in the model.

\section{Materials and methods}

\section{Animals}

Male Sprague-Dawley rats (4-5 weeks old) with an average body mass of $130 \mathrm{~g}$ (provided by the Center for Experimental Animals, Research Institute of Surgery, Third Military Medical University, China) were housed in a room at a constant temperature of $22 \pm 2^{\circ} \mathrm{C}$, humidity $55-56 \%$, with a 12-h light-dark cycle and free access to standard pellet chow and water. All animal procedures were in accordance with the guidelines for the care and use of laboratory animals approved by the Third Military Medical University, China.
Experimental protocol and sample collection

Rats were randomly divided into control, ADR nephrosis, and simvastatin-treated ADR nephrosis groups. ADR nephrosis was induced by a single-tail intravenous injection of ADR $(6.5 \mathrm{mg} / \mathrm{kg}$ body weight; diluted to $50 \%$ with $0.9 \%$ saline; Pharmacia, Italia). The control rats were injected with a comparable volume of $0.9 \%$ saline. Simvastatin at $3 \mathrm{mg} / \mathrm{kg}$ body weight dissolved in a $0.06 \%$ solution of $0.9 \%$ saline was administered once a day by gavage. This dosage was selected because it does not affect serum lipids levels in Sprague-Dawley rats [11]. Control and ADRnephrosis rats received $0.9 \%$ saline $5 \mathrm{ml} / \mathrm{kg}$ once a day by gavage. Treatment was started 6 days after ADR injection and continued throughout the experiment. On the $0,6,13$, 27,55 , and 83 days, the animals were placed in individual metabolic cages for 24-h urine collection. During urine collection, rats were deprived of food to avoid contamination of the urine but were allowed free access to water. Under chloral hydrate anesthesia $(300 \mathrm{mg} / \mathrm{kg}$ intraperitoneally), the rats were sacrificed at $14,28,56$, and 84 days after ADR injection. Blood was collected from the femoral artery, serum was prepared via centrifugation at $850 \mathrm{~g}$ for $15 \mathrm{~min}$ at $4^{\circ} \mathrm{C}$, and stored at $-20^{\circ} \mathrm{C}$ until further analysis. Renal tissue was topical hypothermia perfused with cold $0.9 \%$ saline $10-15 \mathrm{ml}$ until renal tissue became pale, and then was removed. The upper pole of the right kidney was fixed in $10 \%$ formaldehyde for routine histological examination and immunohistochemical study, and part of the renal cortex was fixed in 3\% glutaraldehyde for transmission electron microscopy examination. After separating renal medulla, the middle proportion of the right kidney was kept in liquid nitrogen for ribonucleic acid (RNA) analysis, and the lower pole of the right kidney was homogenized for cytokine analysis. The renal homogenate $(10 \% \mathrm{w} / \mathrm{v})$ was suspended in phosphate-buffered saline (PBS) solution. After centrifugation at $2,500 \mathrm{~g}$ at $4{ }^{\circ} \mathrm{C}$ for $15 \mathrm{~min}$, the supernatant was collected and stored at $-20^{\circ} \mathrm{C}$.

Biochemical analysis

The 24-h urinary protein excretion was measured using the Coomassie brilliant blue method. Serum albumin (ALB), total cholesterol (TC), triglyceride (TG), low-density lipoprotein (LDL), and creatinine (Cr) were measured using an automatic biochemical analyzer (Dimension RxL, Dade Behring Inc., USA).

Histopathological examination

The fixed tissue specimens were dehydrated in graded alcohol, cleared in toluene, and embedded in paraffin. Paraffin sections $(3 \mu \mathrm{m})$ were stained with hematoxylin and 
eosin (H\&E) and periodic acid-Schiff (PAS). Glomerulosclerosis was defined as disappearance of cellular elements from the tufts, collapse of the capillary lumen, and folding of the glomerular basement membrane with entrapment of amorphous material [12]. Severity of glomerulosclerosis was evaluated using an index score that included the percent of glomeruli showing sclerosis and the degree of extension of the glomerulosclerosis within the glomeruli, as described previously by Rodriguez et al. [13]. Briefly, glomeruli were graded from 0 to +4 : grade 0 , normal; grade $1,<25 \%$ involvement of the glomerular tuft; grade 2, 25$50 \%$ involvement; grade 3, 50-75\% involvement; and grade 4 , sclerosis occupying $>75 \%$ of the glomerular tuft. The glomerulosclerosis score was obtained as follows: [ $(1 \times$ number of glomeruli with +1$)+(2 \times$ number of glomeruli with +2$)+(3 \times$ number of glomeruli with +3$)+(4 \times$ number of glomeruli with +4$)] \times 100 \% /$ total number of glomeruli examined. In each kidney specimen, approximately 30 glomeruli were examined in cortical and juxtamedullary areas selected at random. Histopathological evaluation was made in a blinded fashion by an investigator.

The renal cortex was immediately fixed in 3\% glutaraldehyde in cacodylate buffer for $2 \mathrm{~h}$, postfixed in $1 \%$ osmium tetroxide for $1 \mathrm{~h}$, dehydrated in graded ethanol, washed in acetone, and embedded in Epon 812. Ultrathin sections for ultrastructural examination were stained with uranyl acetate and lead citrate and examined with a transmission electron microscope (H-7600; Hitachi, Tokyo, Japan) at $75 \mathrm{kV}$. Renal specimens at 2, 4, and 12 weeks from each group were observed.

\section{Immunohistochemical analysis of IL- $1 \beta$ and TGF- $\beta 1$}

Immunohistochemistry (two-step method) was used to observe IL- $1 \beta$ and TGF- $\beta 1$ expression. In brief, renal cortical paraffin sections $(3 \mu \mathrm{m})$ were deparaffinized and rehydrated, treated with $0.3 \% \mathrm{H}_{2} \mathrm{O}_{2}$ in methanol for $15 \mathrm{~min}$ to quench endogenous peroxide activity, and boiled at $100^{\circ} \mathrm{C}$ for $10 \mathrm{~min}$ in $10 \mathrm{mM}$ citrate buffer ( $\mathrm{pH} \mathrm{6.0)}$ ) to unmask antigens. Sections were incubated with rabbit anti-rat IL-1 $\beta$ antibody (working dilution 1:100; sc-7884, Santa Cruz, USA) or rabbit anti-rat TGF- $\beta 1$ (working dilution 1:100; sc146) at $4^{\circ} \mathrm{C}$ overnight, followed by horseradish-peroxidaselabeled polymer conjugated to secondary goat anti-rabbit antibody at $37^{\circ} \mathrm{C}$ for $30 \mathrm{~min}$ (PV-6001, Zhongshan, China). Sections were visualized with diaminobenzidene (DAB) reagent and counterstained with hematoxylin. PBS was substituted for primary antibodies as negative control, whereas the positive control was from confirmed positive tissue specimens.

Quantification of TGF- $\beta 1$ immunostaining was performed by calculating the proportion of area occupied by the brown staining in all glomeruli or tubular area per section using the Image-Pro Plus System associated with a video camera and computer, as described previously by Qin [14].

RNA isolation and reverse transcription polymerase chain reaction (RT-PCR) examination

Total RNA was isolated from frozen kidney according to the manufacturer's protocol (R6311-01, Genemega, USA). Gel electrophoresis and ethidium bromide staining confirmed the purity and integrity of the samples. Quantification of RNA was based on spectrophotometric analysis at 260/280 nm. Then, $2 \mu \mathrm{g}$ of total RNA were reverse-transcribed with $0.5 \mu \mathrm{l}$ reverse transcriptase (DRR037S, TaKaRa, China) using random 6 mers and oligo dT primer as primers in a $10 \mu$ reaction mixture following the manufacturers instructions. The complementary deoxyribonucleic acid (cDNA) was used as a template in Multiplex polymerase chain reaction (PCR) reaction with housekeeping $\beta$-actin gene as an internal control.

PCR was performed in $25 \mu \mathrm{l}$ of reaction solution containing $0.25 \mathrm{mM}$ deoxynucleoside triphosphate (dNTP), $1.5 \mathrm{mM}$ magnesium chloride $\left(\mathrm{MgCl}_{2}\right), 0.05 \mathrm{U}$ Taq polymerase, $10 \mathrm{mM}$ Tris hydrochloride $(\mathrm{HCl})(\mathrm{pH} 8.3)$, and $50 \mathrm{mM}$ potassium chloride $(\mathrm{KCl})$ (all from TIANGEN, China), 50 pmol of each rat-specific oligonucleotide primers (all from Invitrogen, China) and reverse transcriptase (RT) products ( $1 / 5$ of RT reaction). IL- $1 \beta$ and $\beta$-actin primers were designed from published rat sequences $[15$, 16]. They were as follows: for the IL-1 $\beta$ 5' primer, 5'CTGTGACtCGTGGgatgatG-3', and 3' primer, 5'GGGATTTTGTCGTTGCTTGT-3'; and for the $\beta$-actin 5' primer, 5'-TTCTACAATGAGCTGCGTGTGG-3', and the 3' primer, 5'-ATACCCAGGAAGGAAGGCTGGAAG-3'. The sizes of the reaction products were $210 \mathrm{bp}$ for IL-1 $\beta$ and $539 \mathrm{bp}$ for $\beta$-actin. PCR for IL- $1 \beta$ and $\beta$-actin were performed according to the following cycle: the samples were heated to $94^{\circ} \mathrm{C}$ for $4 \mathrm{~min}$, followed by 30 temperature cycles. Each cycle consisted of denaturation $94^{\circ} \mathrm{C}$ for $1 \mathrm{~min}$, annealing $60^{\circ} \mathrm{C}$ for $1 \mathrm{~min}$, and extension $72^{\circ} \mathrm{C}$ for $1 \mathrm{~min}$. After 30 reaction cycles, the extension reaction was continued for another $5 \mathrm{~min}$.

PCR products were analyzed by electrophoresis on $1.5 \%$ agarose gel containing $0.005 \%$ GoldView $^{\mathrm{TM}}$, and the gels were photographed under ultraviolet light. The bands were visualized with Quantity One ChemiDocXRS (Bio-Rad, USA) and quantified by image analysis software (Quantity One). The relative intensity of bands for IL- $1 \beta$ was normalized using the intensity of $\beta$-actin, calculated as the ratio of the intensity values of each target product to that of $\beta$-actin.

Measurement of IL-1 $\beta$ in serum and kidney

The levels of IL-1 $\beta$ in serum and kidney were detected by enzyme-linked immunosorbent assay (ELISA) kit (BMS630, 
Bender, Austria), with a detection limit of $4.4 \mathrm{pg} / \mathrm{ml}$. All specimens were assayed in duplicate according to the instructions provided by the manufacturer.

\section{Protein quantification by Western blotting}

The nuclei extracts were isolated from renal cortex according to the manufacturer's protocol (K266, Bioision, USA). Protein samples $(75 \mu \mathrm{g} / \mathrm{lane})$ were denatured and subjected to electrophoresis on a 5\% stacking and $10 \%$ separating sodium dodecyl sulfate-polyacrylamide gel in a Bio-Rad mini Protein II apparatus. Electrophoretic transfer to polyvinylidine difluoride membrane was accomplished at $1 \mathrm{~mA} / \mathrm{cm}^{2}$ membrane for $1 \mathrm{~h}$ in $48 \mathrm{mmol} / 1$ Tris, $39 \mathrm{mmol} / 1$ glycine, $0.037 \%$ sodium dodecyl sulfate (SDS), and $20 \%$ methanol. The membrane was then blocked with $5 \%$ skimmed milk for $1 \mathrm{~h}$ at room temperature, followed by two 5-min washes in TBST (Tris-buffered saline/0.1\% Tween-20). The membrane was incubated with primary antibody against nuclear factor kappa B (NF-kB) p65 (ab31407, ABCAM, UK) at 1:600 dilution or against $\beta$ actin (M611, JingMei, Chian) at 1:5,000 dilution at $4^{\circ} \mathrm{C}$ overnight, followed by three 5 -min washes in TBST. A goat anti-rabbit horseradish-peroxidase-conjugated antibody (GAR007, MultiScience, China) at 1:5,000 dilution was added to the membrane for $1 \mathrm{~h}$ at room temperature, followed by three 5-min washes in TBST. Finally, detection procedures were performed using Chemiluminescent Substrate Kit (LumiGLO, USA), and autoradiography was performed on Quantity One ChemiDocXRS (Bio-Rad). Band intensity volumes (\% adjustment) were measured by Quantity One software.

\section{Statistical analysis}

The software used for statistical analysis was SPSS for Windows 13.0. Groups of data were analyzed using one-way analysis of variance (ANOVA) followed by the StudentNewman-Keuls test. Qualitative data was analyzed by the Kruskal-Wallis test. Values of $P<0.05$ were regarded as significant.

\section{Results}

\section{Biochemical findings}

As shown in Fig. 1, compared with the control rats, the ADR-nephrosis rats developed marked proteinuria at 2 weeks after ADR injection, which peaked at 8 weeks, and then decreased slightly at 12 weeks. The simvastatintreated nephrosis rats showed a trend toward a decrease in 24-h urinary protein excretion with a significant fall at 4

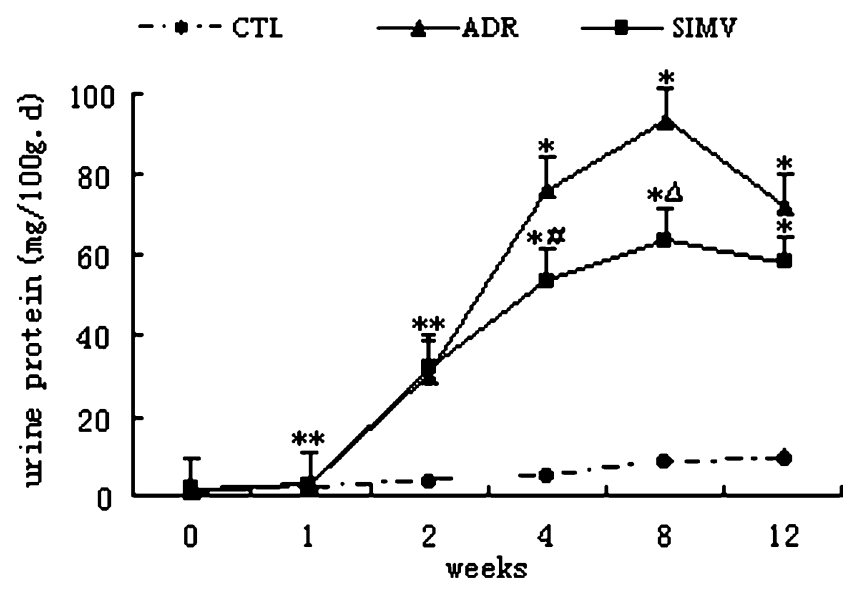

Fig. 1 Twenty-four-hour proteinuria levels after Adriamycin (ADR) injection. Marked proteinuria developed at 2 weeks after injection, peaked at 8 weeks, and then decreased slightly at 12 weeks. The simvastatin-treated ADR-nephrosis rats showed a trend toward a decrease in 24-h urinary protein excretion, with significant difference at 4 and 8 weeks. Each group consisted of eight rats; values represent mean \pm standard error of mean. CTL control, $A D R$ untreated ADR nephrosis, SIMV simvastatin-treated ADR nephrosis. ${ }^{*} P<0.01$ vs. control; ${ }^{\#} P<0.05,{ }^{\Delta} P<0.01$ vs. untreated ADR nephrosis in the same experimental day, respectively

and 8 weeks, although without reaching significance at 12 weeks. Both untreated and simvastatin-treated nephrosis rats exhibited marked hypoalbuminemia (Fig. 2a) and hyperlipidemia (Fig. 2b-d). The level of serum albumin in the simvastatin-treated group was higher than in the untreated group at 2, 4, 8, and 12 weeks and was significantly higher at 8 weeks $(P<0.01)$. There were no significant differences found in serum TC, TG, and LDL between untreated and simvastatin-treated nephrosis rats. Serum $\mathrm{Cr}$ concentration in untreated nephrotic rats was higher than in control rats at 8 and 12 weeks $(P<0.05, P<0.01$, respectively). Serum $\mathrm{Cr}$ concentration in simvastatin-treated rats did not significantly increase until 12 weeks when compared with control rats and was lower than in untreated rats $(P<0.05)$ at 12 weeks (Fig. 2e). During the treatment period, untreated and simvastatin-treated nephrotic rats gained weight slowly when compared with the control rats; however, simvastatin-treated nephrotic rats gained more weight than untreated rats in the same experimental period (Fig. 2f).

Histopathological findings

Under light microscopy, kidneys from control rats were histologically normal (Fig. 3a,d), and there were no obvious lesions found in kidneys from untreated and simvastatintreated nephrosis rats at 2 and 4 weeks. Whereas untreated rats demonstrated glomerulosclerosis and renal tubular injury from 8 weeks, the renal injury had become increasingly serious by 12 weeks. Glomerular changes consisted of collapse of glomerular tufts, glomerular tufts adhering to 
Fig. 2 Levels of serum albumin (ALB), total cholesterol (TC), triglycerides (TG), low-density lipoprotein (LDL), creatinine (Cr), and body weight. Each group consisted of eight rats; values represent mean \pm standard error of mean. CTL control, $A D R$ untreated ADR nephrosis, SIMV simvastatintreated ADR nephrosis.. ${ }^{*} P<$ $0.01,{ }^{\Delta} P<0.05$ vs. control; ${ }^{\Delta} P<0.01,{ }^{\#} P<0.05$ vs. untreated ADR nephrosis in the same experimental day, respectively a
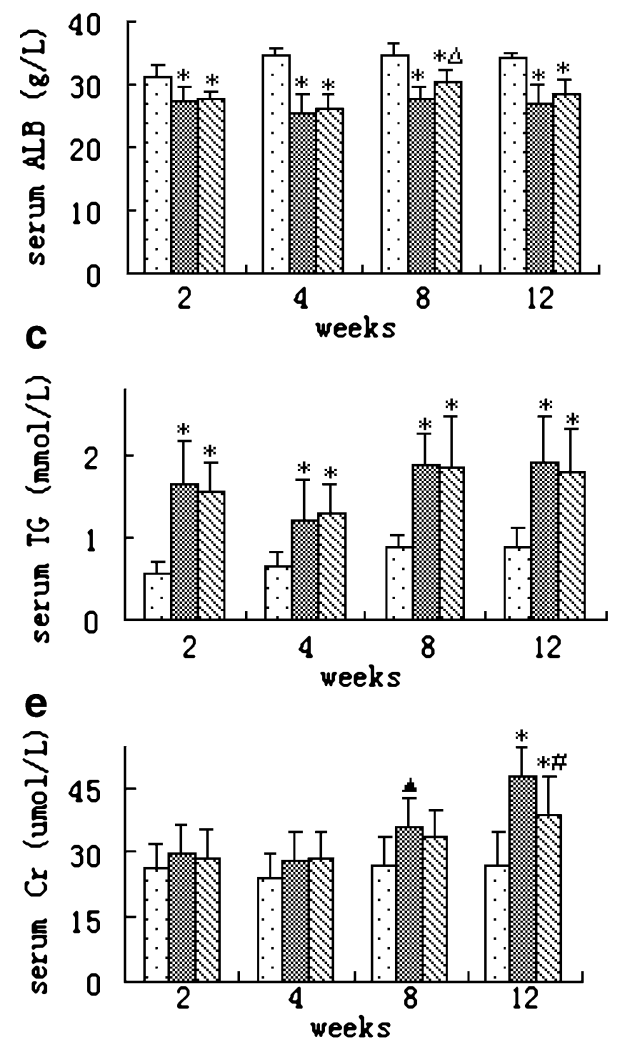

$\square C T L$ O ADR $8 \mathrm{SDT}$

b
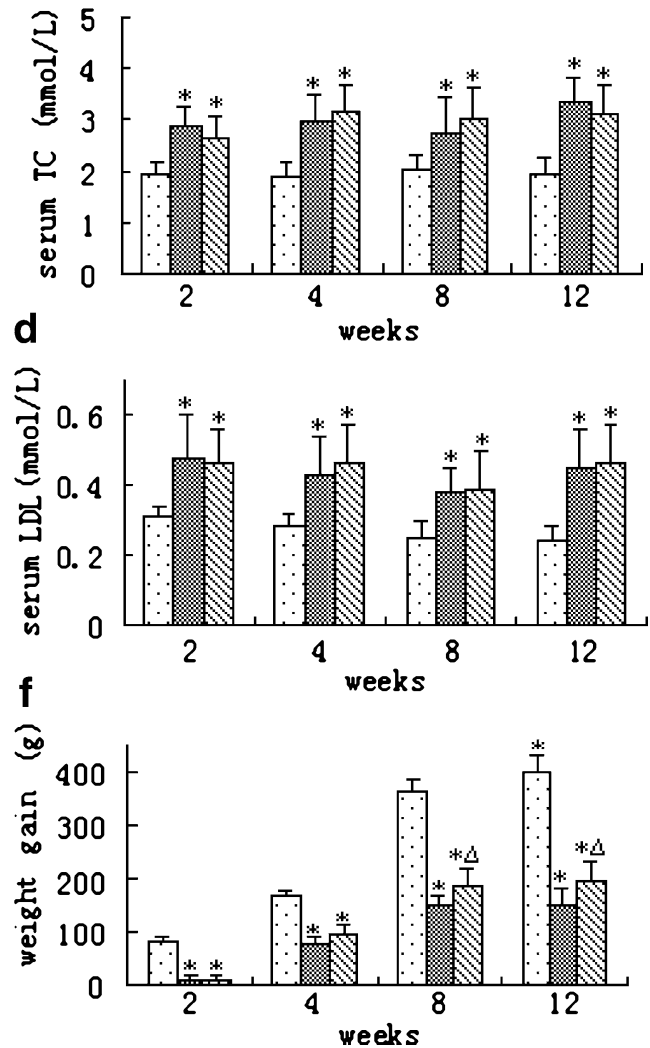

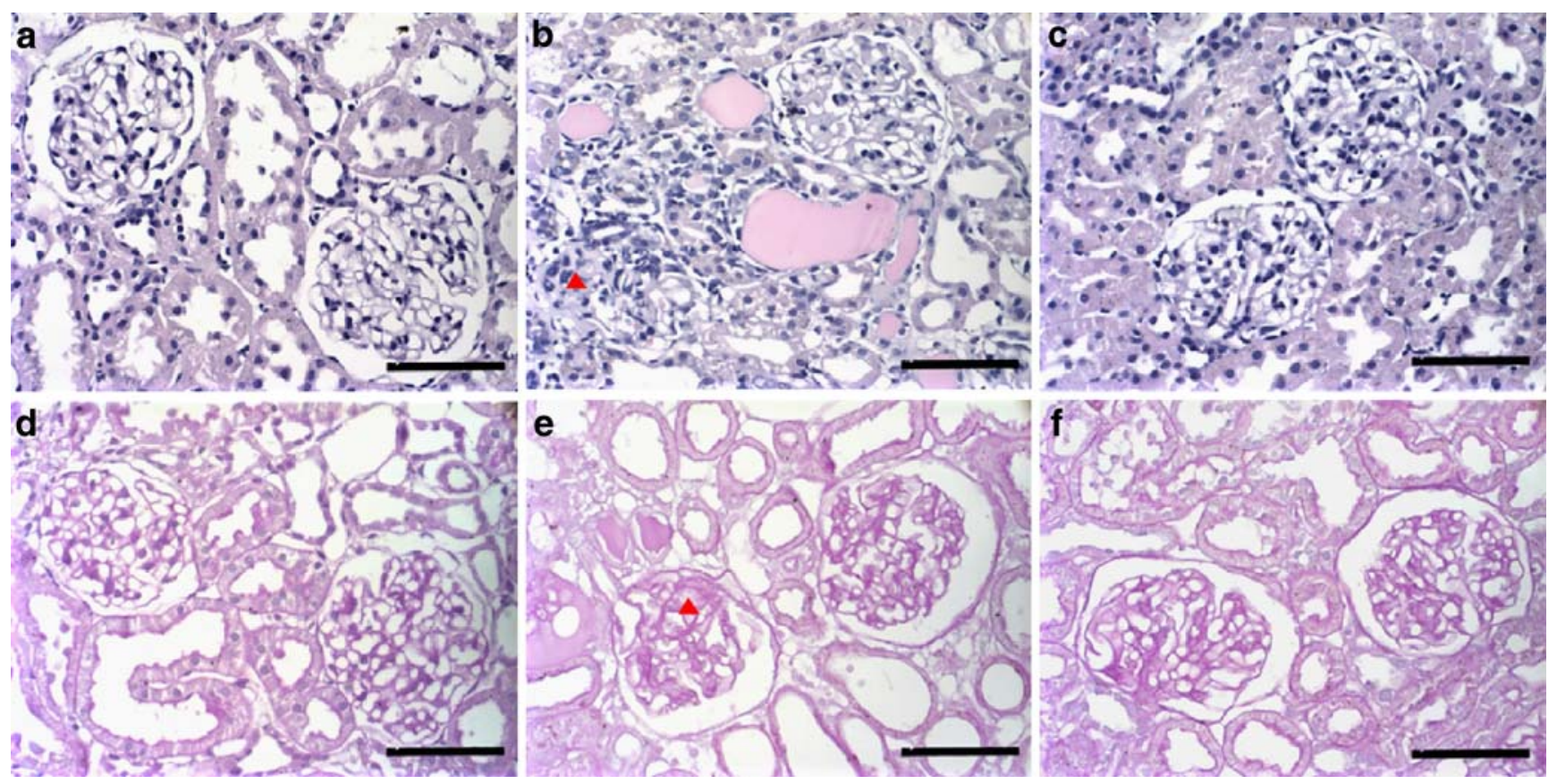

Fig. 3 Light microscopy of renal tissues in control (a, d), untreated nephrosis $(\mathbf{b}, \mathbf{e})$ and simvastatin-treated nephrosis $(\mathbf{c}, \mathbf{f})$ at 12 weeks after Adriamycin injection (a-c, hematoxylin \& eosin; $\mathbf{d}-\mathbf{f}$, periodic
acid-Schiff). The untreated nephrotic rats showed glomeruli with focal segmental glomerulosclerosis (arrow). Magnification bars $50 \mu \mathrm{m}$ 
Bowman's space, and mild mesangial expansion. Consistent with the high level of albuminuria, significant tubular dilation associated with large proteinaceous casts and tubular atrophy were also noted. Glomerular and renal interstitial injury were accompanied by patches of leukocyte infiltration (Fig. 3b,e). In the nephrosis rats receiving simvastatin, lesions were markedly reduced compared with untreated rats (Fig. 3c,f). The untreated rats had higher glomerulosclerosis indexes $(8.40 \pm 2.33 \%$ vs. $0.78 \pm 0.28 \%$ in the control rats at 8 weeks, $P<0.01$, and $15.65 \pm 4.75 \%$ vs. $0.96 \pm 0.34 \%$ in the control rats at 12 weeks, $P<0.01$ ). Compared with the untreated rats, treatment with simvastatin significantly attenuated the glomerulosclerosis index $(5.19 \pm 2.04 \%$ at 8 weeks, $P<0.01$, and $9.14 \pm 4.25 \%$ at 12 weeks, $P<0.01$ ).

\section{Ultrastructural change}

Compared with the control rats (Fig. 4a), in ADR-nephrosis rats at 2 weeks, the normal arrangement of interdigitating foot processes was lost and the foot processes broadened (Fig. 4b); at 4 weeks, widespread fusion and effacement of foot processes appeared (Fig. 4c). All changes observed were limited to podocyte and glomerular basement membrane, whereas endothelial and mesangial cells did not show marked changes on electron microscopy, which is similar to human MCNS. At 12 weeks, untreated rats showed podocyte swelling, cytoplasmic lysis, lipid drop deposition, and mitochondria intracristal space expansion besides the fusion and effacement of foot processes (Fig. 4d). Lesions in simvastatin-treated rats were markedly reduced when compared with untreated rats (Fig. 4e).

\section{Expression of IL-1 $\beta$}

In control rats (Fig. 5a), only faint staining for IL-1 $\beta$ was observed in renal tubular epithelial cells, and there was no obvious increase in either untreated or simvastatin-treated rats at 2 and 4 weeks. However, IL-1 $\beta$ expression in untreated rat kidneys increased by 8 weeks and remarkably so by 12 weeks (Fig. 5b), and IL-1 $\beta$ was found mainly in glomerular cells and renal tubular epithelial cells, with almost no positive renal interstitial expression. IL-1 $\beta$ expression in simvastatin-treated rats was substantially weaker than in untreated rats in the same experimental day (Fig. 5c). Compared with the control group, IL-1 $\beta$ messenger RNA (mRNA) expression increased by $59.6 \%$ and $117.4 \%$ in the untreated group at 8 and 12 weeks, and $33.7 \%$ and $60.0 \%$ in simvastatin-treated group in the same experimental period, respectively (Fig. 6). IL-1 $\beta$ levels in renal homogenate supernatant and serum at 8 and 12 weeks were quantitatively detected by ELISA (Table 1). No significant differences were found between serum IL-1 $\beta$ concentrations in controls, untreated, and simvastatin-treated rats. However, renal concentration of IL-1 $\beta$ increased by $36.3 \%$ and $84.5 \%$ in the untreated group at 8 and 12 weeks and $20.1 \%$ and $44.6 \%$ in the simvastatin-treated group in the same experimental day compared with the control group, respectively.

\section{Expression of TGF- $\beta 1$ in kidney}

As with IL- $1 \beta$ expression in the kidney, TGF- $\beta 1$ expression in untreated nephrotic rat kidneys increased at 8 weeks and remarkably so by 12 weeks (Fig. 5e). Untreated rats had an increased glomerulus and tubulus immunostaining for TGF$\beta 1$ when compared with control rats at 12 weeks (untreated $13.44 \pm 1.83 \%$ vs. control, $1.65 \pm 0.28 \%, P<0.01$; Fig. 5 d). Simvastatin treatment was associated with reduced immunostaining for TGF- $\beta 1$ when compared with untreated rats at 12 weeks $(8.57 \pm 1.26 \%, P<0.05$ vs. untreated; Fig. 5 f).

NF- $\mathrm{BB}$ p65 protein expression in renal cortex

To evaluate NF-kB activity, we examined nuclear p65 protein expression in renal cortex of rats at 12 weeks by

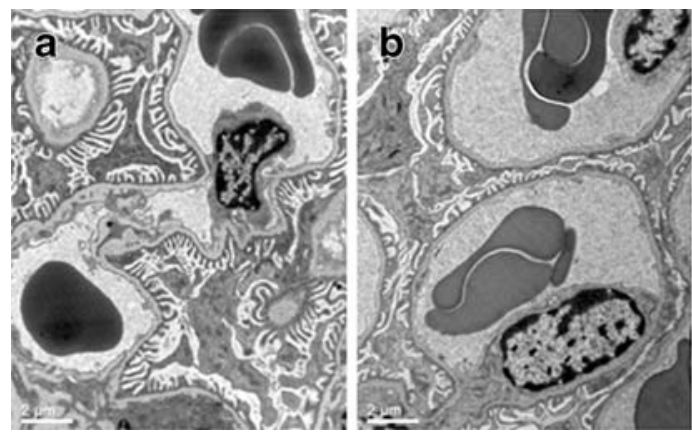

Fig. 4 Morphological change in the podocyte foot process under transmission electron microscopy. Foot processes in the control rats were tall and narrow (a). At 2 weeks after Adriamycin injection, foot processes broadened (b). Fusion and effacement of foot processes was observed at 4 weeks after Adriamycin injection (c). Fusion and effacement of foot processes accompanying with podocyte swelling,
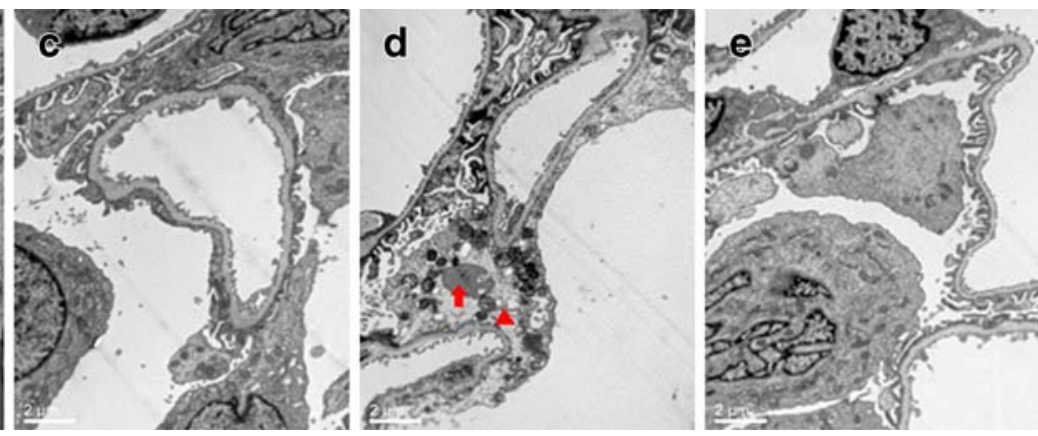

cytoplasmic lysis (arrow) and lipid drop deposition (arrowhead) and mitochondria intracristal space expansion in the untreated rats at 12 weeks (d). Simvastatin-treated rats showed moderate fusion and effacement of foot processes and no podocyte cytoplasm lysis (e). Magnification bars $2 \mu \mathrm{m}$ 


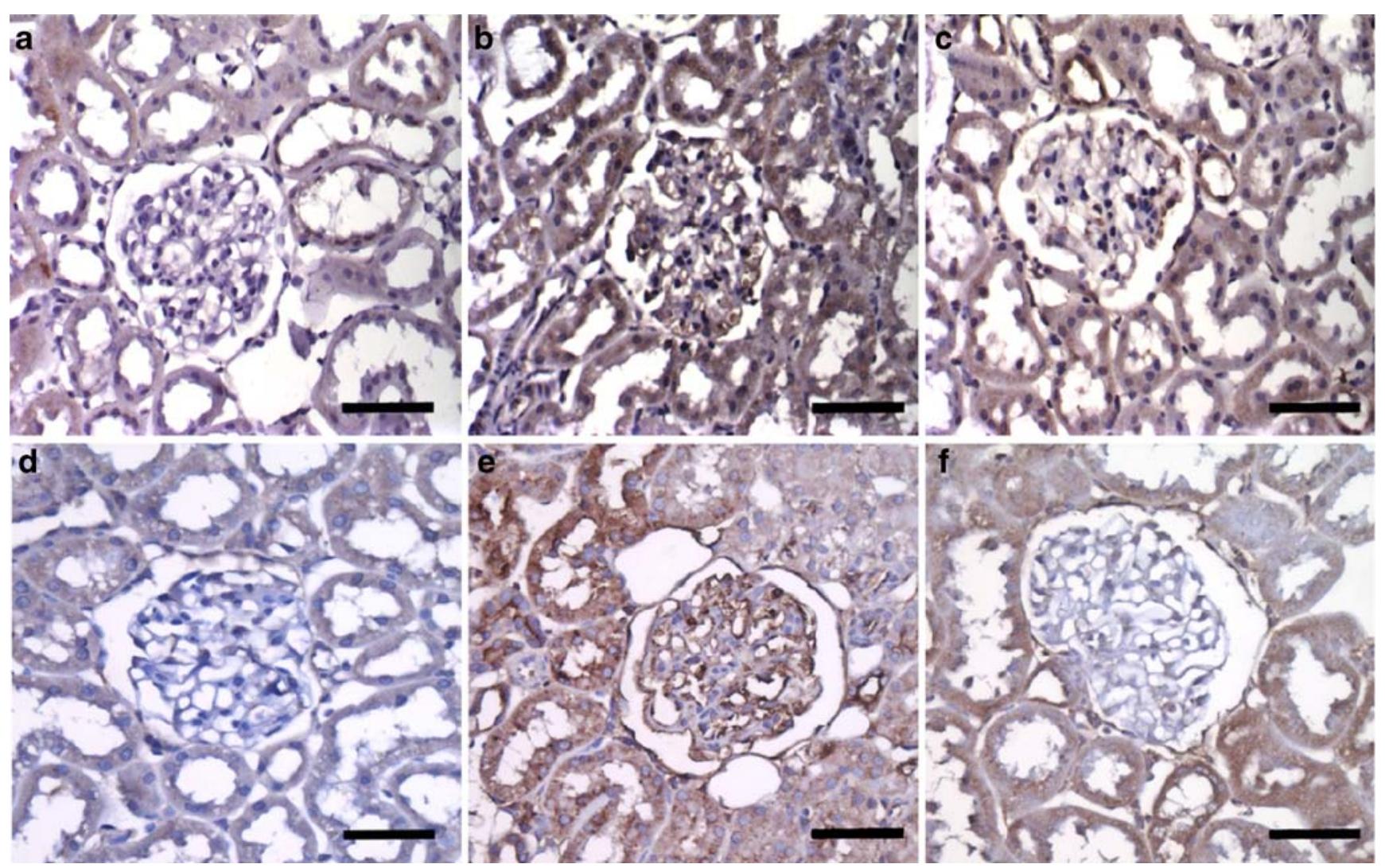

Fig. 5 Immunostaining for interleukin-1 beta (IL-1 $\beta$ ) in control (a), untreated (b), and simvastatin-treated (c); and transforming growth factor beta (TGF- $\beta$ ) in control (d), untreated (e) and simvastatin-

Western blotting (Fig. 7a). As shown in Fig. 7b, p65 levels in untreated rats was significantly higher than those in control and simvastatin-treated rats. Treatment with simvastatin significantly decreased the level of p65.

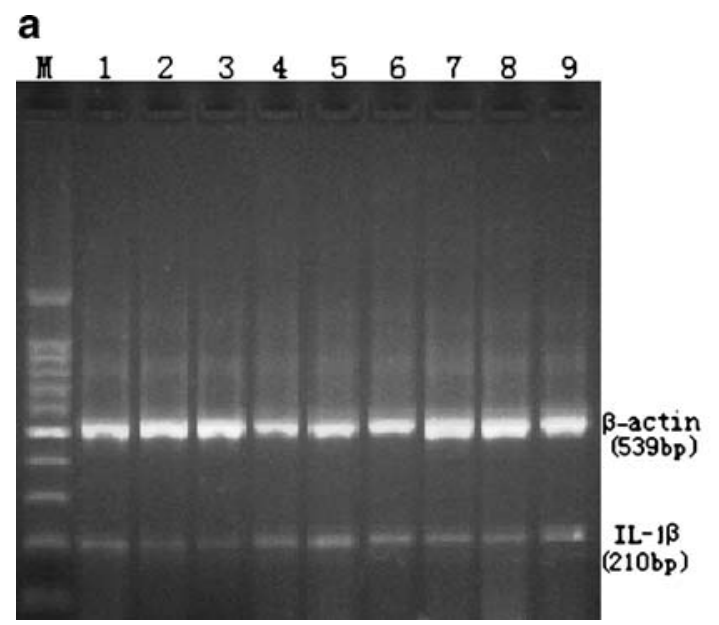

Fig. 6 Renal messenger ribonucleic acid (mRNA) expression of interleukin-1 beta (IL-1 $\beta$ ) at 12 weeks by reverse transcriptase polymerase chain reaction (RT-PCR). $M$ molecular weight marker (a). Lanes 1-3 control (CTL), Lanes 4-6 untreated Adriamycin (ADR) nephrosis $(A D R)$, Lanes 7-9 simvastatin-treated ADR nephrosis

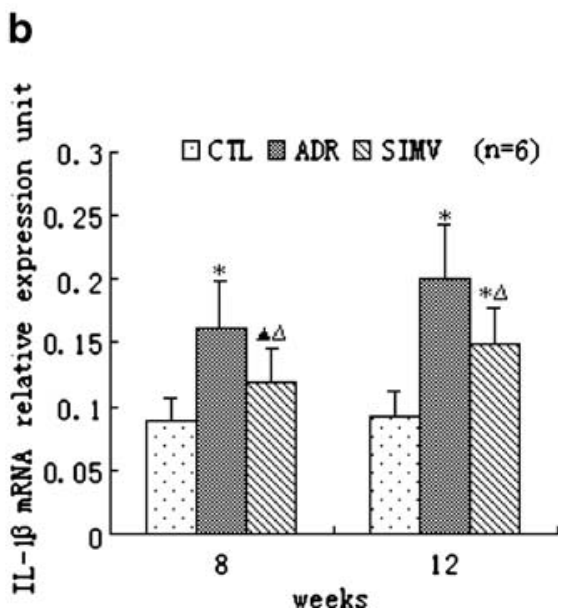

treated (f) rats at 12 weeks after Adriamycin injection. Magnification bars $50 \mu \mathrm{m}$

\section{Discussion}

In this study, we used the ADR model of MCNS. A single injection of ADR resulted in massive proteinuria,

(SIMV). IL-1 $\beta$ mRNA levels from RT-PCR relative to the housekeeping gene, $\beta$-actin (b). Each group consisted of six rats; values represent mean \pm standard error of mean. ${ }^{*} P<0.01,{ }^{\mathbf{\Delta}} P<0.05$ vs. control; ${ }^{\Delta} P<0.01$ vs. untreated ADR nephrosis in the same experimental day 
Table 1 Interleukin-1 beta (IL-1 $\beta$ ) levels in serum and renal tissue at glomerulosclerosis stage

\begin{tabular}{llllll}
\hline Groups & \multicolumn{2}{l}{ Serum $(\mathrm{pg} / \mathrm{ml})$} & & \multicolumn{2}{l}{ Renal homogenate supernatant $(\mathrm{pg} / \mathrm{ml})$} \\
\cline { 2 - 3 } & Week 8 & Week 12 & Week 8 & Week 12 \\
\hline CTL & $39.35(12.18-377.66)$ & $54.45(33.35-163.44)$ & & $424.18 \pm 93.81$ & $422.17 \pm 104.19$ \\
ADR & $84.34(5.48-859.77)$ & $117.04(37.68-917.73)$ & & $578.03 \pm 96.16^{*}$ & $786.09 \pm 227.32^{* *}$ \\
SIMV & $47.90(24.99-310.09)$ & $124.60(10.36-295.74)$ & & $509.36 \pm 163.36$ & $616.26 \pm 128.99 * * * *$ \\
$H$ or $F$ value & 0.285 & 2.830 & 3.187 & 10.052 \\
$P$ value & 0.867 & 0.243 & 0.062 & 0.001 \\
\hline
\end{tabular}

Each group consisted of eight rats, the values in serum expressed as median and range, and the values in renal homogenate supernatant represent mean \pm standard error of mean

$C T L$ control, $A D R$ untreated Adriamycin (ADR) nephrosis, SIMV simvastatin-treated ADR nephrosis

$* P<0.05, * * P<0.01$ vs. control; ***P<0.05 vs. untreated ADR nephrosis in the same experimental day

hypoalbuminemia, hyperlipidemia, and decreased renal function, indicating progressive renal failure. We also noted the development of focal segmental glomerulosclerosis and renal tubular injury from 8 weeks to 12 weeks after ADR injection, accompanied by increasing renal IL- $1 \beta$, TGF- $\beta 1$, and NF- $\mathrm{KB}$ expression. In contrast, simvastatin treatment reduced urinary protein excretion and prevented loss of renal function while ameliorating glomerulosclerosis and renal tubular injury in parallel with reduction of IL- $1 \beta$, TGF- $\beta 1$, and NF- $\mathrm{kB}$ expression in glomerular and renal tubular cells. Notably, these changes occurred in the absence of the lowering of serum lipids, suggesting a direct renoprotective effect of simvastatin on ADR-nephrosis rats.

MCNS was proposed to be a disorder of T-cell dysfunction by Shalhoub in 1974 [17]. Unlike inflammatory renal glomerular diseases, which elicit a wide spectrum of inflammatory and metabolic activities, MCNS has no systemic inflammation and no immune complex deposition in the glomeruli. There was no increase in serum IL-1 $\beta$, a proinflammatory cytokine that triggers inflammatory processes by activating a wide range of inflammatory mediators, in our ADR-nephrosis rats, which accords with pathobiology of ADR nephrosis. Massive proteinuria and hyperlipidemia are important manifestations of nephrotic syndrome, and protein and lipids escaping through damaged glomeruli could activate intrinsic renal cells to secret cytokines. By immunohistochemistry, we found that IL-1 $\beta$ positive expression was mainly located in glomerular and tubular cells but almost never in renal interstitial cells. The finding that intrinsic renal cells are the major source of IL- $1 \beta$ synthesis in normal and diseased rat kidney $[18,19]$ is consistent with these data. IL-1 $\beta$ can induce mesangial cell proliferation and extracellular matrix production and activate parietal cells of Bowman's capsule and tubular and interstitial cells to release additional chemokines, leading to invasion of the urinary space and interstitial tissue by $\mathrm{T}$ cells, macrophages, and fibroblasts. The resulting damage to parietal and visceral epithelial cells and tubular interstitial tissue leads to irreversible sclerosis [1]. Studies in murine crescentic glomerulonephritis $(\mathrm{GN})$ indicate that IL-1 $\beta$ is the major proinflammatory cytokine-mediating glomerular injury [20]. The benefits of inhibiting IL-1 using anti-IL-1 antibodies [21], soluble IL-1 receptor, or IL-1-receptor antagonist [22] have been shown in experimental GN. Our data revealed that increasing IL-1 $\beta$ expression accompanied severe glomerulosclerosis and renal tubular cell injury in untreated ADR-nephrosis rats, whereas mild and moderate glomerulosclerosis and renal tubular cell injury with weak IL-1 $\beta$ expression were found in the renal tissue of simvastatin-treated ADR-nephrosis rats. Taken together, strong upregulation of IL-1 $\beta$ expression, particularly in

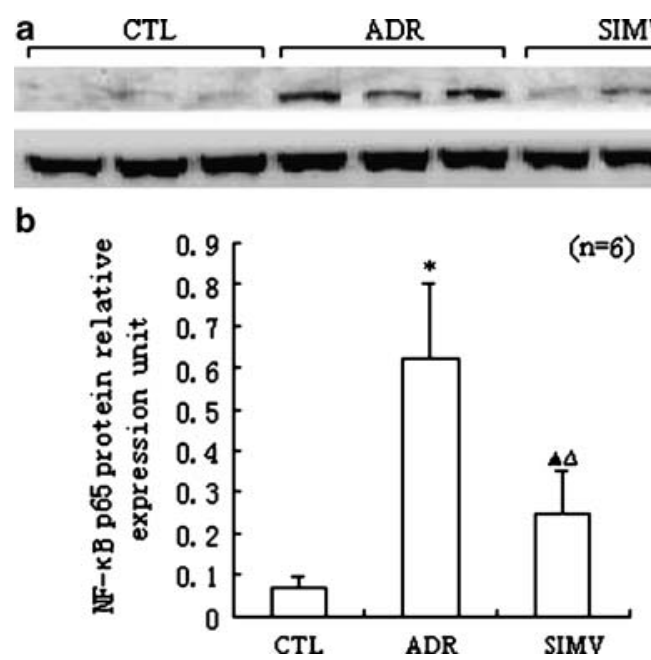

Fig. 7 Expression of nuclear p65 protein in renal cortex by Western blotting. Levels of nuclear p65 protein in control group (CTL), untreated group [Adriamycin (ADR)], and simvastatin-treated group (SIMV) (a). Nuclear p65 protein levels from Western blotting relative to the housekeeping gene, $\beta$-actin (b). Each group consisted of six rats; values represent mean \pm standard error of mean. CTL control group, $A D R$ untreated group, SIMV simvastatin-treated group. ${ }^{*} P<$ $0.01,{ }^{\Delta} P<0.05$ vs. control; ${ }^{\triangle} P<0.01$ vs. untreated ADR nephrosis in the same experimental day 
glomerular areas and accompanying tubular damage, at least, may be an important trigger for glomerulosclerosis in ADR-induced nephrosis in rats. Simvastatin can attenuate glomerulosclerosis, and its renoprotective effect may partly contribute to decreased renal IL- $1 \beta$ expression. Importantly, simvastatin did not change plasma lipids levels in our study. These data support the hypothesis that simvastatin has anti-inflammatory and antiglomerulosclerotic activities independent of plasma lipid lowering.

Simvastatin treatment reduced transcription factor NF$\kappa \mathrm{B}$ activation in this study. NF- $\kappa \mathrm{B}$ is a rapid-response transcription factor that promotes expression of a number of genes involved in inflammation, such as cytokines, chemokines, and adhesion molecules [23]. A previous study revealed that NF- $\mathrm{B}$ B plays a pivotal role in the pathophysiology of renal diseases [24]. In nephropathy, many factors such as filtered albumin, LDL, and ox-LDL contribute to $\mathrm{NF}-\mathrm{KB}$ activation in renal cells [24, 25]. The constitutive activation of the NF- $\mathrm{KB}$ pathway is often associated with increased expression of a variety of inflammatory genes, including IL- $1 \beta$, which is activated by and activates NF- $\kappa B$ [23]. This type of positive regulatory loop may amplify and perpetuate local kidney inflammatory responses. A recent study suggested that statins possess anti-inflammatory properties that involve NF-KB inhibition [26]. Therefore, we investigated the effect of simvastatin on NF- $\mathrm{KB}$ activation as reflected by $\mathrm{p} 65$ in the renal cortex. NF- $\mathrm{KB}$ exists in the cytoplasm as a heterodimer of a $50-\mathrm{kDa}(\mathrm{p} 50)$ and a $65-$ $\mathrm{kDa}(\mathrm{p} 65)$ subunit associated with an inhibitory protein of the IкB family. When cells are stimulated, the I $\mathrm{kB}$ inhibitory protein is phosphorylated, and it dissociates from the NF- $\mathrm{KB}$ heterodimer. Free NF- $\mathrm{kB}$ then translocates into the nucleus and induces target gene expression [23]. We found by Western blotting that simvastatin inhibited p65 expression in the nuclei of the renal cortex of nephrotic rats, suggesting that simvastatin may down-regulate IL-1 $\beta$ expression by inhibiting NF- $\mathrm{kB}$ activation.

TGF- $\beta 1$ has been consistently suggested to play a key role in the pathogenesis of glomerulosclerosis and tubulointerstitial fibrosis in progressive renal disease. Our study confirmed an increase in TGF- $\beta 1$ expression in the untreated nephrotic kidney and further demonstrated that this increase was prevented by simvastatin.

Several lines of evidence indicate that statins reduce proteinuria $[25,27,28]$. In our study, urinary protein excretion was significantly reduced by simvastatin from 4 weeks to 8 weeks; however, urinary protein excretion decreased in both untreated and simvastatin-treated rats at 12 weeks, and the degree of decrease in simvastatin-treated rats was less than in untreated rats. MCNS is characterized by high glomerular basement membrane (GBM) permeability secondary to diffuse fusion and effacement of podocyte foot processes. With the development of glomerulosclerosis, urinary protein excretion decreases because of the GBM permeability decrease and less protein filtering. The degree of urinary protein excretion decrease in simvastatin-treated rats was less than in untreated rats at 12 weeks, which indirectly demonstrated that simvastatin can ameliorate glomerulosclerosis in ADR-induced-nephropathy rats.

Although we reported the renoprotective effect of simvastatin on ADR-induced-nephropathy rats for the first time, a couple of questions remain to be answered. We intend to establish an inflammation model of ADR-induced-nephropathy rats . We will then investigate the relationship between NF- $\kappa B$ expression and simvastatin treatment in cultured cells to further describe which molecular mechanisms are responsible for glomerulosclerosis in this animal model and whether NF$\mathrm{KB}$ plays a central role in the mediation of the anti-inflammatory effect of simvastatin. We will use other methods such as in situ hybridization to further delineate which cells are responsible for the inflammatory effect and which cells are influenced by simvastatin in ADR-induced-nephropathy rats.

\section{Conclusion}

Overexpression of inflammation in renal region may contribute to development of glomerulosclerosis in ADR-inducednephropathy rats, and simvastatin treatment prevented glomerulosclerosis, independent of the lipids-lowering effects. The beneficial effect of simvastatin might be mediated by the effect of anti-inflammatory action through a reduction of NF- $\mathrm{kB}$ activation, IL- $1 \beta$ and TGF- $\beta$ expression. The precise mechanisms of simvastatin's renoprotective effect on ADR induced-nephrosis rats remain further investigation.

Acknowledgments This study was financially supported by the National Natural Science Foundation of China (grant no. 30672267).

Open Access This article is distributed under the terms of the Creative Commons Attribution Noncommercial License which permits any noncommercial use, distribution, and reproduction in any medium, provided the original author(s) and source are credited.

\section{References}

1. Segerer S, Nelson PJ, Schlondorff D (2000) Chemokines, chemokine receptors, and renal disease: from basic science to pathophysiologic and therapeutic studies. J Am Soc Nephrol 11: 152-176

2. Rubartelli A, Cozzolino F, Talio M, Sitia R (1990) A novel secretory pathway for interleukin-1 beta, a protein lacking a signal sequence. EMBO J 9:1503-1510

3. Franzen R, Pautz A, Brautigam L, Geisslinger G, Pfeilschifter J, Huwiler A (2001) Interleukin-1beta induces chronic activation and de novo synthesis of neutral ceramidase in renal mesangial cells. J Biol Chem 276:35382-35389 
4. Goldstein JL, Brown MS (1990) Regulation of the mevalonate pathway. Nature 343:425-430

5. Byington RP, Jukema JW, Salonen JT, Pitt B, Bruschke AV, Hoen H, Furberg CD, Mancini GB (1995) Reduction in cardiovascular events during pravastatin therapy. Pooled analysis of clinical events of the Pravastatin Atherosclerosis Intervention Program. Circulation 92: 2419-2425

6. Shepherd J, Cobbe SM, Ford I, Isles CG, Lorimer AR, MacFarlane PW, McKillop JH, Packard CJ (1995) Prevention of coronary heart disease with pravastatin in men with hypercholesterolemia. West of Scotland Coronary Prevention Study Group. N Engl J Med 333:1301-1307

7. Usui H, Shikata K, Matsuda M, Okada S, Ogawa D, Yamashita T, Hida K, Satoh M, Wada J, Makino H (2003) HMG-CoA reductase inhibitor ameliorates diabetic nephropathy by its pleiotropic effects in rats. Nephrol Dial Transplant 18:265-272

8. Harris KP, Purkerson ML, Yates J, Klahr S (1990) Lovastatin ameliorates the development of glomerulosclerosis and uremia in experimental nephrotic syndrome. Am J Kidney Dis 15:16-23

9. Li C, Yang CW, Park JH, Lim SW, Sun BK, Jung JY, Kim SB, Kim YS, Kim J, Bang BK (2004) Pravastatin treatment attenuates interstitial inflammation and fibrosis in a rat model of chronic cyclosporineinduced nephropathy. Am J Physiol Renal Physiol 286:F46-F57

10. Jasinska M, Owczarek J, Orszulak-Michalak D (2007) Statins: a new insight into their mechanisms of action and consequent pleiotropic effects. Pharmacol Rep 59:483-499

11. Zoja C, Corna D, Rottoli D, Cattaneo D, Zanchi C, Tomasoni S, Abbate M, Remuzzi G (2002) Effect of combining ACE inhibitor and statin in severe experimental nephropathy. Kidney Int 61: $1635-1645$

12. Chen A, Sheu LF, Ho YS, Lin YF, Chou WY, Chou TC, Lee WH (1998) Experimental focal segmental glomerulosclerosis in mice. Nephron 78:440-452

13. Rodriguez-Iturbe B, Quiroz Y, Shahkarami A, Li Z, Vaziri ND (2005) Mycophenolate mofetil ameliorates nephropathy in the obese Zucker rat. Kidney Int 68:1041-1047

14. Qin J, Zhang Z, Liu J, Sun L, Hu L, Cooper ME, Cao Z (2003) Effects of the combination of an angiotensin II antagonist with an HMG-CoA reductase inhibitor in experimental diabetes. Kidney Int 64:565-571

15. Navarro JF, Milena FJ, Mora C, Leon C, Garcia J (2006) Renal pro-inflammatory cytokine gene expression in diabetic nephropathy: effect of angiotensin-converting enzyme inhibition and pentoxifylline administration. Am J Nephrol 26:562-570

16. Ye S, Mozayeni P, Gamburd M, Zhong H, Campese VM (2000) Interleukin-1beta and neurogenic control of blood pressure in normal rats and rats with chronic renal failure. Am J Physiol Heart Circ Physiol 279:H2786-H2796

17. Shalhoub RJ (1974) Pathogenesis of lipoid nephrosis: a disorder of T-cell function. Lancet 2:556-560

18. Tesch GH, Yang N, Yu H, Lan HY, Foti R, Chadban SJ, Atkins RC, Nikolic-Paterson DJ (1997) Intrinsic renal cells are the major source of interleukin-1 beta synthesis in normal and diseased rat kidney. Nephrol Dial Transplant 12:1109-1115

19. Niemir ZI, Stein H, Dworacki G, Mundel P, Koehl N, Koch B, Autschbach F, Andrassy K, Ritz E, Waldherr R, Otto HF (1997) Podocytes are the major source of IL-1 alpha and IL-1 beta in human glomerulonephritides. Kidney Int 52:393-403

20. Timoshanko JR, Kitching AR, Iwakura Y, Holdsworth SR, Tipping PG (2004) Contributions of IL-1beta and IL-1alpha to crescentic glomerulonephritis in mice. J Am Soc Nephrol 15:910-918

21. Karkar AM, Koshino Y, Cashman SJ, Dash AC, Bonnefoy J, Meager A, Rees AJ (1992) Passive immunization against tumour necrosis factor-alpha (TNF-alpha) and IL-1 beta protects from LPS enhancing glomerular injury in nephrotoxic nephritis in rats. Clin Exp Immunol 90:312-318

22. Karkar AM, Tam FW, Steinkasserer A, Kurrle R, Langner K, Scallon BJ, Meager A, Rees AJ (1995) Modulation of antibodymediated glomerular injury in vivo by IL-1 ra, soluble IL-1 receptor, and soluble TNF receptor. Kidney Int 48:1738-1746

23. Barnes PJ, Karin M (1997) Nuclear factor-kappaB: a pivotal transcription factor in chronic inflammatory diseases. N Engl $\mathrm{J}$ Med 336:1066-1071

24. Guijarro C, Egido J (2001) Transcription factor-kappa B (NFkappa B) and renal disease. Kidney Int 59:415-424

25. Shibata S, Nagase M, Fujita T (2006) Fluvastatin ameliorates podocyte injury in proteinuric rats via modulation of excessive Rho signaling. J Am Soc Nephrol 17:754-764

26. Kleemann R, Verschuren L, de Rooij BJ, Lindeman J, de Maat MM, Szalai AJ, Princen HM, Kooistra T (2004) Evidence for antiinflammatory activity of statins and PPARalpha activators in human C-reactive protein transgenic mice in vivo and in cultured human hepatocytes in vitro. Blood 103:4188-4194

27. Bussolati B, Deregibus MC, Fonsato V, Doublier S, Spatola T, Procida S, Di Carlo F, Camussi G (2005) Statins prevent oxidized LDL-induced injury of glomerular podocytes by activating the phosphatidylinositol 3-kinase/AKT-signaling pathway. J Am Soc Nephrol 16:1936-1947

28. Nakamura $T$, Ushiyama $C$, Hirokawa $K$, Osada $S$, Inoue $T$, Shimada N, Koide H (2002) Effect of cerivastatin on proteinuria and urinary podocytes in patients with chronic glomerulonephritis. Nephrol Dial Transplant 17:798-802 